\title{
Land Characterization Analysis of Surface Temperature of Semi-Arid Mountainous City Abha, Saudi Arabia Using Remote Sensing and GIS
}

\author{
Javed Mallick \\ Assistant Professor, Department of Civil Engineering, Faculty of Engineering, King Khalid University, \\ Abha, KSA \\ Email: javnaffi@gmail.com
}

Received 27 September 2014; revised 24 October 2014; accepted 20 November 2014

Copyright (c) 2014 by author and Scientific Research Publishing Inc.

This work is licensed under the Creative Commons Attribution International License (CC BY). http://creativecommons.org/licenses/by/4.0/

(c) (i) Open Access

\section{Abstract}

This knowledge of land surface temperature and its spatial variations within a city environment is of prime importance to the study of urban climate and human-environment interactions. Few studies have examined the influence of land use and terrain on the surface temperature effects of semi-arid mountainous urban areas. This study investigates the urban environment characterization and its effects on surface temperature using remote sensing. The methodologies adapted for this study are geometric and radiometric corrections of satellite data, extraction of land use/land cover and digital elevation model, estimation of vegetation density using Normalized Difference Vegetation Index (NDVI), and estimation of surface temperature and emissivity using temperature emissivity separation (TES) algorithm. Finally geospatial model and statistical techniques are used for assessing the overall impact of urban environmental characterization on urban climate of semi-arid region of Abha, Kingdom of Saudi Arabia. Herein, results reveal that the spatial distribution of surface temperature was affected by land use/land cover (LULC) and topography. The high dense built-up and commercial/industrial areas display higher surface temperature in comparison with surrounding lands. There is gradual decrease of LULC classes' surface temperature with the increase in altitude. The cooling effect towards the surrounding urban built-up area is found increasing at the hill located vegetated area, the downward slope and valley terrain inside the recreational park. Therefore the spatial variation in surface temperature also reflected the effects of topography on LULC classes. Suitable mountainous land use utilization would help to expand the cooling effect. In the future, the outcomes of this study could be used to build environmentally sustainable urban planning suitable to semi-arid regions and to create practices that consider the local weather environment in urban planning. 


\section{Keywords}

\section{Land Surface Temperature, Land Use/Land Cover, Normalized Difference Vegetation Index, Mountainous Semi-Arid City GIS}

\section{Introduction}

Land surface temperature is an important factor in global environmental change studies in estimating radiation budgets in heat balance studies and as a control for climate models [1]. Thermal infrared (TIR) remote sensing data can provide important measurements of land surface heat fluxes and surface temperature which are integral to understanding landscape processes and responses [2]. There are many satellite sensors, which are able to sense thermal infrared radiation (TIR) with different spectral and spatial resolution [3]. The use of satellite thermal remote sensing in the estimation of the surface physical properties and other related variables is investigated by Carlson et al. [4], Balling and Brazel [5], Dousset [6] [7], Roth et al. [8], Quattrochi and Ridd [9], Owen et al. [10], and Voogt and Oke [11], Mallick et al. [1]. Satellites with medium spatial resolutions are used particularly at the regional scale. For this purpose, medium resolution thermal infrared imagery/data, LANDSAT TM/ETM+, and ASTER have been extensively used to study surface temperature (Ts) variations and to relate them to land cover characteristics [12]. Emissivity and surface temperature enables the better understanding of the overall urban land use/land cover classes and in turn helps in understanding the energy budget issues [13].

Weng et al. [14] utilized a LANDSAT ETM+ image $60 \mathrm{~m}$ thermal infrared data to examine relationship between the land surface temperature (LST) and vegetation abundance in Indianapolis. Mallick et al. [1] utilized ASTER image of $90 \mathrm{~m}$ thermal data to evaluate the spatial and temporal variation in surface temperature associated with impervious surface area (ISA) and assess the effect of urbanization on the local climate.

Topography is an important influencing factor controlling surface temperature [15]. Lookingbill and Urban [16] suggested a site-specific model for estimating temperature differences across a complex topography. There is also research study related to the use of satellite based assessment for modeling of topo-climate [17]. The general factors of local topography are elevation, latitude, aspect and slope, which are commonly in-situ measurement [18]. Elevation and latitude influence the general climatological characteristics, such as annual mean temperature, annual precipitation, temperature minimum and temperature maximum. Average temperatures drop by about $6.4^{\circ} \mathrm{C}$ per $\mathrm{km}$, but this varies from region to region [19]. The local effects of slope and aspect, which influence the potential radiation and heat load are commonly computed in ecological studies [20], mostly based on DEM [21]. As per the geological setting of the study area i.e., weak geology, due to slopes, rainfall pattern of last 2 decades and fast urbanization, the area has severe problem of land degradation and consequently affecting the forestlands, the productivity of agriculture, sedimentation and water qualities of catchment areas [22] [23]. As per the literature survey, there are few studies that have examined the influence of land use and topography on the Ts effects of semi-arid mountainous urban areas.

Interpreting and analyzing the thermal satellite data and images for thermal pattern over an area is a complex one. In some cases, one must look for pattern of relative temperature differences rather than the absolute values because of the many complex factors that make quantitative determinations complicated; for example number and spatial distribution of different material surfaces in an instantaneous field of view (IFOV). As thermal response depends on composition, density and texture of the materials; vegetation canopy characteristics, including height, leaf geometry, and plant shape, and near surface (1 to 3 meters) air temperature, relative humidity, and wind effects [24]. There is a gap of an understanding about the spatially continuous view of surface UHI over Abha mountainous city, which is a fast sprawling city [25]. This thermal behavior of landscape surfaces over the course of a day would yield a remarkable database for urban planners and architects for improving city site quality by making it more eco-friendly. This would be particularly beneficial to country like Saudi Arabia and some other with semi-arid climate. In the present study, we focused on the modeling of the influence of topography on surface temperature. The objective of this study is to investigate the spatial distribution property of the Ts with spatial information related with land use/land cover, vegetation density, and altitudinal effects, in the semi-arid mountainous city Abha using ASTER remote sensing data and GIS spatial analysis. 


\section{Overview of Study Area and Data}

The city of Abha is situated in Aseer province in south-western Saudi Arabia. It covers an area of $370 \mathrm{~km}^{2}$. Its boundary lies between the latitude $18^{\circ} 10^{\prime} 12.39^{\prime \prime} \mathrm{N}$ and $18^{\circ} 23^{\prime} 33.05^{\prime \prime} \mathrm{N}$ and longitude $42^{\circ} 21^{\prime} 41.58^{\prime \prime} \mathrm{E}$ and $42^{\circ} 39^{\prime} 36.09^{\prime \prime} \mathrm{E}$. The topography of the area is mountainous with an elevation range between 1951 meters to 2991 meters mean sea level msl. The average annual rainfall is $355 \mathrm{~mm}$, with the bulk of the precipitation occurring between April and August Aseer can experience temperatures ranging from $1.90^{\circ} \mathrm{C}$ to $34.80^{\circ} \mathrm{C}$ (Table 1). The study area embraces one of the richest and the most variable floristic regions of the Aseer Mountains. Jabal Al-Sooda, a mountain located in the north-western part of the study area, is also rich in biodiversity. The variation in climate and topography in the study area has led to the formation of diverse plant community [26] (Figure 1).

The dataset used in the study is given in Table 2. All data has been converted into raster at 90 meter cell size, so that spatial analysis can be done in the same cell size and map projection. Garmin-38s GPS navigator has been used for field survey to collects the ground control points, GCPs.

\section{Data and Methods Used}

\subsection{Satellite Data Pre-Processing}

ASTER satellite dataset was used in order to effectively identify the spatial distribution characteristics of land cover/land use (LULC) classes and surface temperature for the city of Abha. This study assessed the LULC, normalized difference vegetation index (NDVI) and surface temperature, the spectral radiance value is converted from DN (Digital number) in each pixel by using equation:

$$
L_{\lambda}=(\mathrm{DN}-1) \times \mathrm{UCC}
$$

Table 1. Meteorological data of the study 2012.

\begin{tabular}{ccccc}
\hline 2012 & Extreme Min Air Temperature & $\begin{array}{c}\text { Extreme Max Air } \\
\text { Temperature }\end{array}$ & Mean Air Temperature & Rainfall in MM \\
\hline Jan & 1.90 & 25.40 & 14.10 & 0.00 \\
Feb & 6.10 & 26.30 & 15.90 & 8.80 \\
Mar & 6.50 & 28.40 & 17.20 & 4.60 \\
Apr & 12.00 & 28.40 & 20.30 & 21.40 \\
May & 13.90 & 33.00 & 21.60 & 0.10 \\
Jun & 16.20 & 34.80 & 25.10 & 76.90 \\
Jul & 15.00 & 33.00 & 23.30 & 29.00 \\
Aug & 13.10 & 32.50 & 23.40 & 0.10 \\
Sep & 12.00 & 31.90 & 22.60 & 0.90 \\
Oct & 10.60 & 29.30 & 20.00 & 15.50 \\
Nov & 4.00 & 26.50 & 13.10 & 0.00 \\
Dec & 2.90 & 23.70 & & 0.40 \\
\hline
\end{tabular}

Table 2. Datasets.

\begin{tabular}{ccc}
\hline Subject Area & Data Basis & Source \\
\hline Meteorological Data & Monthly temperature and Rainfall data from Abha stations & Presidency Meteorological \\
& 2012, Latitude: $18^{\circ} 14^{\prime} 17.93$ "N Longitude: $42^{\circ} 39^{\prime} 13.057^{\prime \prime E}$ & Environment KSA \\
Satellite Data Used for LULC, Ts and & ASTER (7 Nov. 2012) & TERRE/ASTER \\
Vegetation Cover & Path/Row $=167 / 47-48$ & NASA \\
Topographical Data & Contour line, spot height, DEM, Mean slope; mean slope & MOMRA, KSA \\
\hline
\end{tabular}




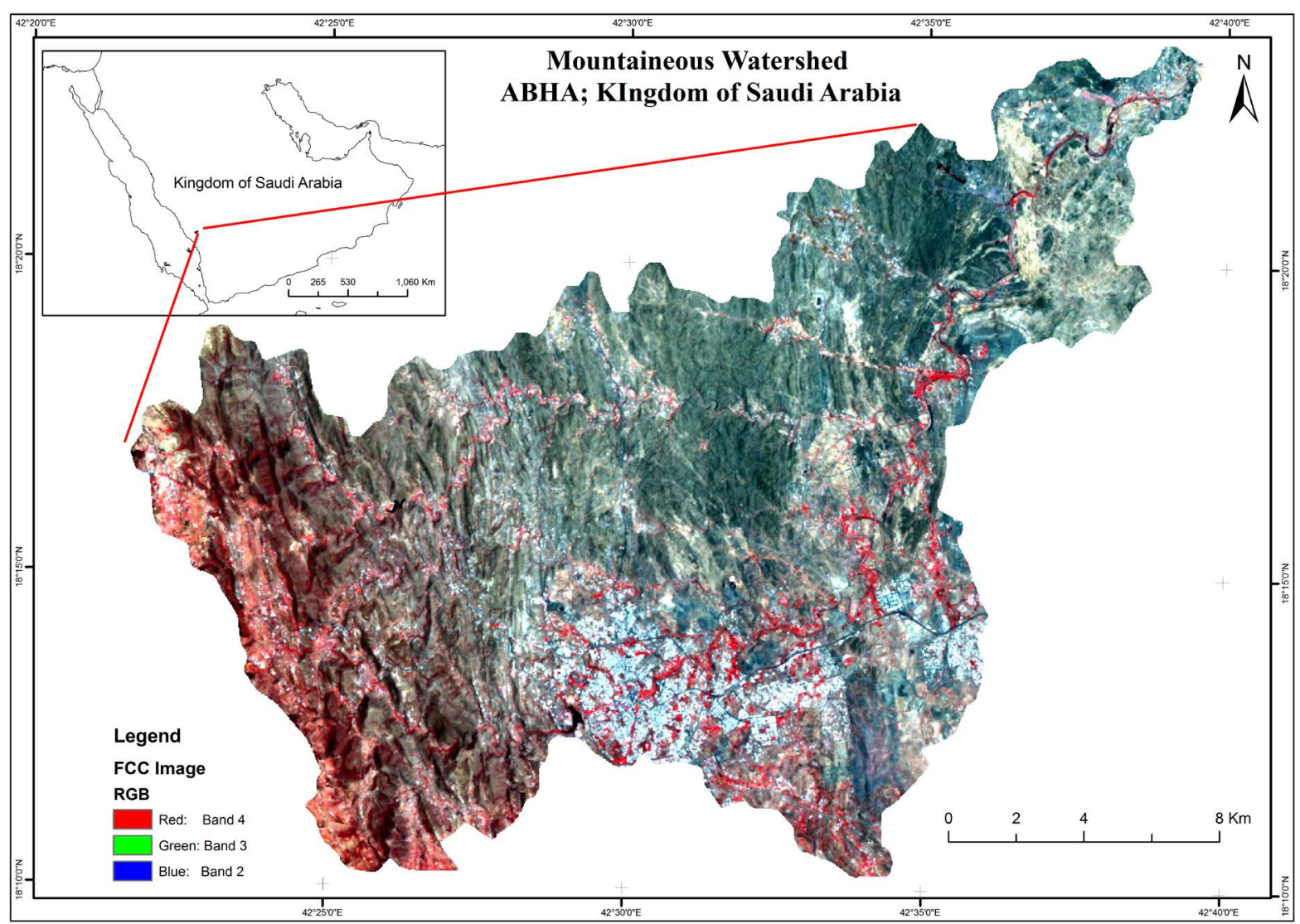

Figure 1. Study area.

where, UCC is unit conversion coefficients from HDF file.

The unit conversion coefficients that are used for different bands and for different gain settings are given in the ASTER user handbook. Thereafter, the satellite image has been geometrically rectified to a common UTM WGS84 coordinate system.

\subsection{Image Classification}

Considering the objectives of the present study, the following classification scheme used for interpreting land use based on Anderson et al., [27] system: built-up land; water bodies; agricultural cropland; dense vegetation (forest); sparse vegetation; fallow land; baresoil/wasteland; bushes and scrubland and rock outcroplands. An extensive field survey was done to identify sample points in the imagery for different LU/LC classes at various locations using navigation system (GPS). Based on the collected sample sets for respective LU/LC classes, training sets were selected for digital image classification using Maximum Likelihood classifier (MLC) technique. To validate the classified LULC, an accuracy assessment has been carried out. For the confusion matrix, derived from image map and field data (signature file), as described by Lillesand et al., [3] was generated for the accuracy assessment. The overall accuracy of LULC map was 88.35 and Kappa coefficient was 0.866.

\subsection{Topographical Data Processing}

The process of digital elevation model (DEM) creation begins with the scanned, geo-referenced Topographic raster Map (1:50,000). Contour Lines with 20 meters interval, spot elevations, from the raster image are extracted, converted to digital vectors and given elevation values. The Grid-based DEM was generated from the extracted digital contour vector data. The DEM was produced with the "Topo to Raster" interpolation techniques using ArcGIS software. This interpolation technique was specially designed for the creation of hydrologically corrected DEM [28]. The range of elevation of the watershed is found to be from 1951 to 2991 meters. The 
maximum height is located in the western part of study area whereas it gradually decreases towards the eastern part.

\subsection{Estimation of Normalized Difference Vegetation Index (NDVI)}

NDVI is the vegetation index used by researchers for extracting vegetation density from remotely sensed data. In essence, the algorithm isolates the dramatic increase in reflectance over the visible red to near infrared wavelengths, and normalizes it by dividing by the overall brightness of each pixel in those wavelengths as shown in the equation:

$$
\mathrm{NDVI}=\frac{(\mathrm{NIR}-\mathrm{R})}{(\mathrm{NIR}+\mathrm{R})}
$$

The values in either band have been converted from raw DN values to reflectance of solar electromagnetic radiation. The result of this algorithm is a single band data, the values ranges from -1 to +1 , where values close to +1 signify greater vegetation cover. The NDVI values are estimated in the range of -0.041 to 0.487 , having a mean value of 0.113 with a standard deviation of 0.046 .

\subsection{Estimation of Ts Using Temperature Emissivity Separation (TES) Algorithm}

In this study, land surface temperature (LST) was estimated from the thermal infrared bands of ASTER satellite dataset using a temperature emissivity separation (TES) model [29]. TES attempts to compensate for reflected down welling irradiance and estimates the absolute spectral emissivity. The additional constraint to overcome the under-determination comes from the regression of the minimum emissivity of spectral contrast (calculated from laboratory spectra), used to equalize the number of unknowns and measurements, so that the set of Planck's equations for the measured thermal radiances can be inverted. ASTER has 14 spectral bands, out of which 5 thermal bands (10 - 14) operate between 8 - $12 \mu \mathrm{m}$. In this study, five emissivity and one surface temperature maps were produced using the TES algorithm. It not only estimates the temperature of homogeneous areas of known emissivity, such as water bodies, but also for heterogeneous areas of unknown emissivity. The spectral radiance of thermal bands at the sensor is calculated using Equation (2).

$$
L S_{j}=\left[\varepsilon_{j} L_{j}^{B B}(T)+\left(1-\varepsilon_{j}\right) L_{j}^{s k y}\right] \times \tau_{j}+L_{j}^{a t m}
$$

where,

$L S_{j}=$ spectral radiance observed by the sensor,

$\varepsilon_{j}=$ surface emissivity at wavelength $j$,

$L_{j}^{B B}(T)=$ spectral radiance from a blackbody at surface temperature $T$,

$L_{j}^{\text {sky }}=$ spectral radiance incident upon the surface from the atmosphere (down welling), from MODTRAN,

$L_{j}^{a t m}=$ spectral radiance emitted by the atmosphere (upwelling), from MODTRAN

$L_{j}^{a t m}=$ spectral atmospheric transmission, from MODTRAN.

At-sensor radiance data were corrected for atmospheric effects to obtain the radiance emitted by the surface $\left(L_{j}\right)$, using the MODTRAN radiative transfer model. The standard atmospheric parameter (tropical climate) has been used. The output parameters obtained have been used to estimate the radiance using Equations (3) \& (4).

$$
L_{j}=\left[L S_{j}-L_{j}^{a t m} \div \tau_{j}\right]-\left(1-\varepsilon_{j}\right) L_{j}^{s k y}=\varepsilon
$$

where, $L_{j}^{B B}(T)=\frac{C_{1}}{\lambda_{j}^{5}\left[\exp \left(C_{2} / \lambda_{j} T\right)-1\right]}$

Hence,

$$
L_{j}=\varepsilon_{j} \times \frac{C_{1}}{\lambda_{j}^{5}\left[\exp \left(C_{2} / \lambda_{j} T\right)-1\right]}
$$

where, 
$C_{1}=$ First radiation constant $=3.74151 \times 10^{-16}$

$C_{2}=$ First radiation constant $=0.0143879(\mathrm{mk})$,

$\lambda_{j}=$ Wavelength of channel $j,(\mathrm{~m})$,

$T=$ Temperature.

In the above equation, if the surface emissivity is known, it is possible to correct for the reflected sky radiation. Then the surface temperature may be calculated using Equation (5).

$$
T_{j}=\frac{C_{2}}{\lambda 1 n}\left[\left(\varepsilon_{j} C_{1} / L_{\lambda} \lambda^{5} \pi\right)+1\right]
$$

The above equation shows that for radiance measured in " $n$ " spectral channels, there will be " $n+1$ " unknowns, " $n$ " emissivities and one surface temperature. In TES [29] the estimated kinetic temperature $T$ is taken to be the maximum temperature estimated from the radiance for the five ASTER TIR spectral bands employing equation 5. An assumed emissivity value (typically 0.97 ) is used in order to be within \pm 0.03 for typical land surfaces (heterogeneous land). The relative emissivities “ $\beta_{j}$ ” have been computed by the following equations:

$$
\beta_{j}=\left(L_{j} / \overline{L_{j}}\right) \times\left(\overline{L^{B B}} / L^{B B}\left(\lambda_{j}, T\right)\right)
$$

where,

$$
\begin{gathered}
\overline{L_{j}}=(1 / 5) \sum_{j=1}^{j=5} L_{j}, \\
L_{j}^{B B}(T)=\frac{C_{1}}{\lambda_{j}^{5}\left[\exp \left(C_{2} / \lambda_{j} T\right)-1\right]} \\
\overline{L^{B B}(T)}=(1 / 5) \sum_{j=1}^{j=5} L_{j}^{B B}(T)
\end{gathered}
$$

For emissivities between $0.7-1.0$, the ratios $\beta_{j}$ are generally within $0.7-1.4$.

The maximum-minimum difference between the emissivity ratios $\beta_{j}$ is given by $M M D=\max \left(\beta_{j}\right)-\min \left(\beta_{j}\right)$. It is observed that MMD ranges from 0.0 to 4.0 at most (Dash et al., 2002). An empirical relation between minimum emissivity and MMD is:

$$
\varepsilon_{\text {min }}=0.994-0.687 \times(M M D)^{0.737}
$$

Therefore, the revised emissivity can be computed using the beta $\left(\beta_{j}\right)$ spectrum as shown below:

$$
\varepsilon_{j}=\beta_{j}\left(\varepsilon_{\min } / \min \left(\beta_{j}\right)\right)
$$

Beta $\left(\beta_{j}\right)$ is determined from the measured surface radiance $L_{j}$ (surface) and new emissivity $\left(\varepsilon_{j}\right)$, to obtained surface temperature. The resultant maps were put into Equation (2) and were processed until equation 11. Thereafter, the process was again repeated so as to arrive at an acceptable emissivity measurement. Based on the above procedures, a detailed model was developed in the ERDAS Imagine to automate the calculation of the surface temperature and five emissivity maps (as the TES algorithm generate) (Figure 2).

\section{Result and Discussion}

\subsection{Analysis of Land Use/Land Cover Class}

Figure 3 shows the most dominant class of LULC in 2012 was the exposed rock (51.29\%) followed by bushes and scrubland (10.96\%), sparse vegetation (10.71\%), and agricultural cropland (4.40\%) The built-up area (9.40\%) is mainly in the central and southeastern part of the study area. This is due to foot hills, water bodies, wadies (dry ephemeral riverbed) and topographically suitable are for infrastructure.

\subsection{Analysis of Surface Temperature}

Figure 4 shows the Ts of ASTER, dated 7th Nov. 2012. The estimated Ts range from $10.68^{\circ} \mathrm{C}$ to $34.58^{\circ} \mathrm{C}$ with 


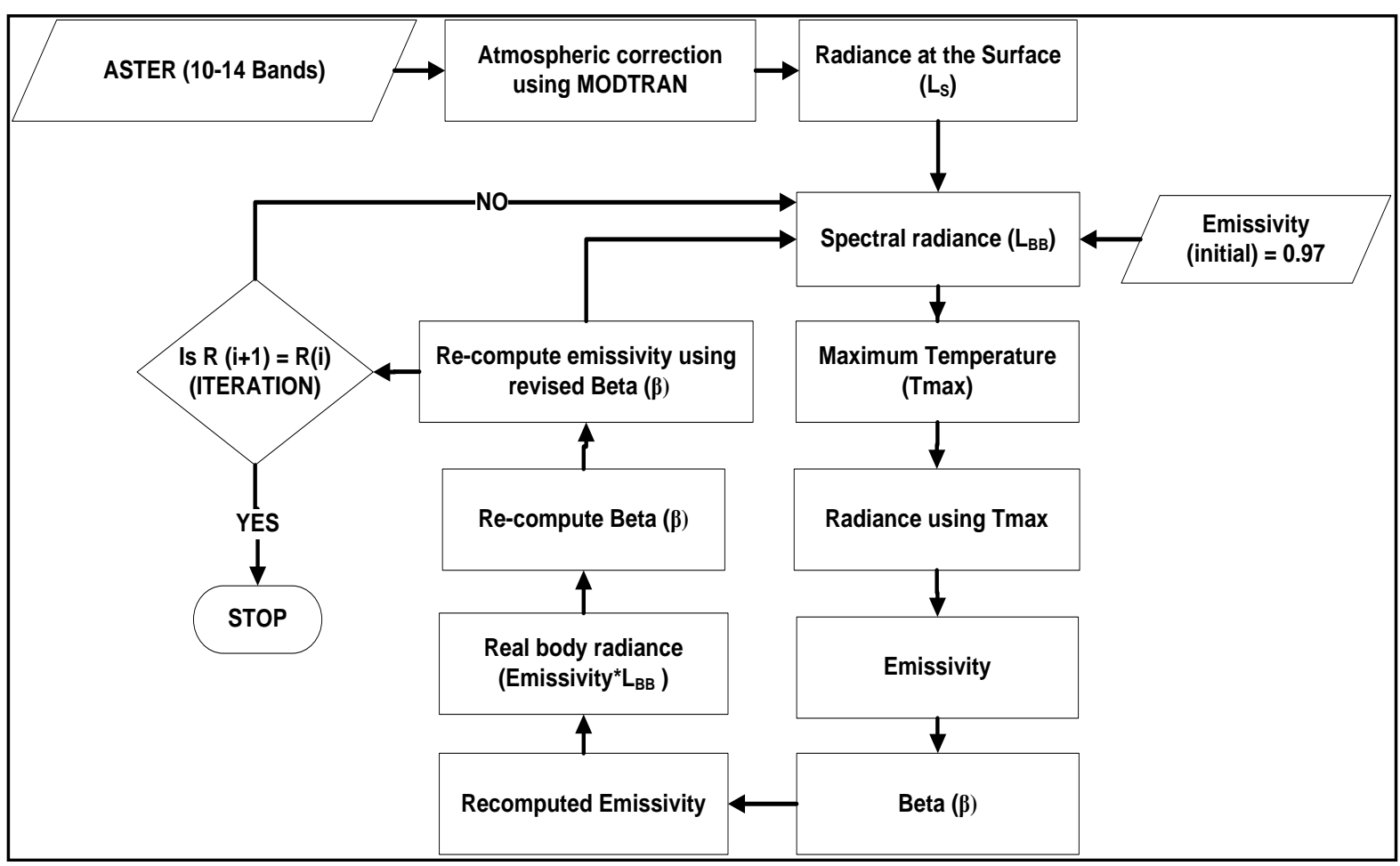

Figure 2. Flow Chart for deriving surface temperature (TES) using ASTER data.

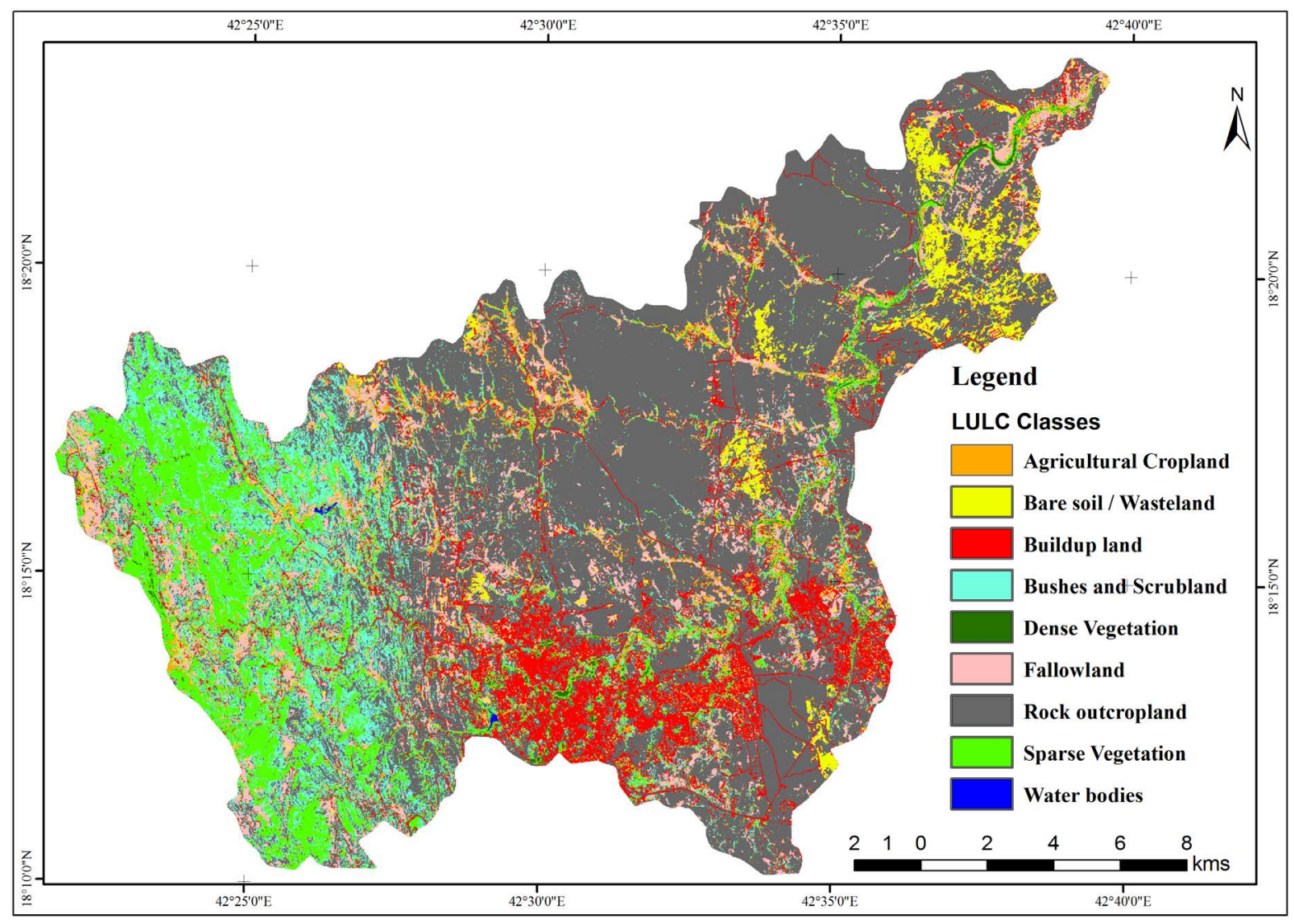

Figure 3. LULC from ASTER satellite data, 2012. 


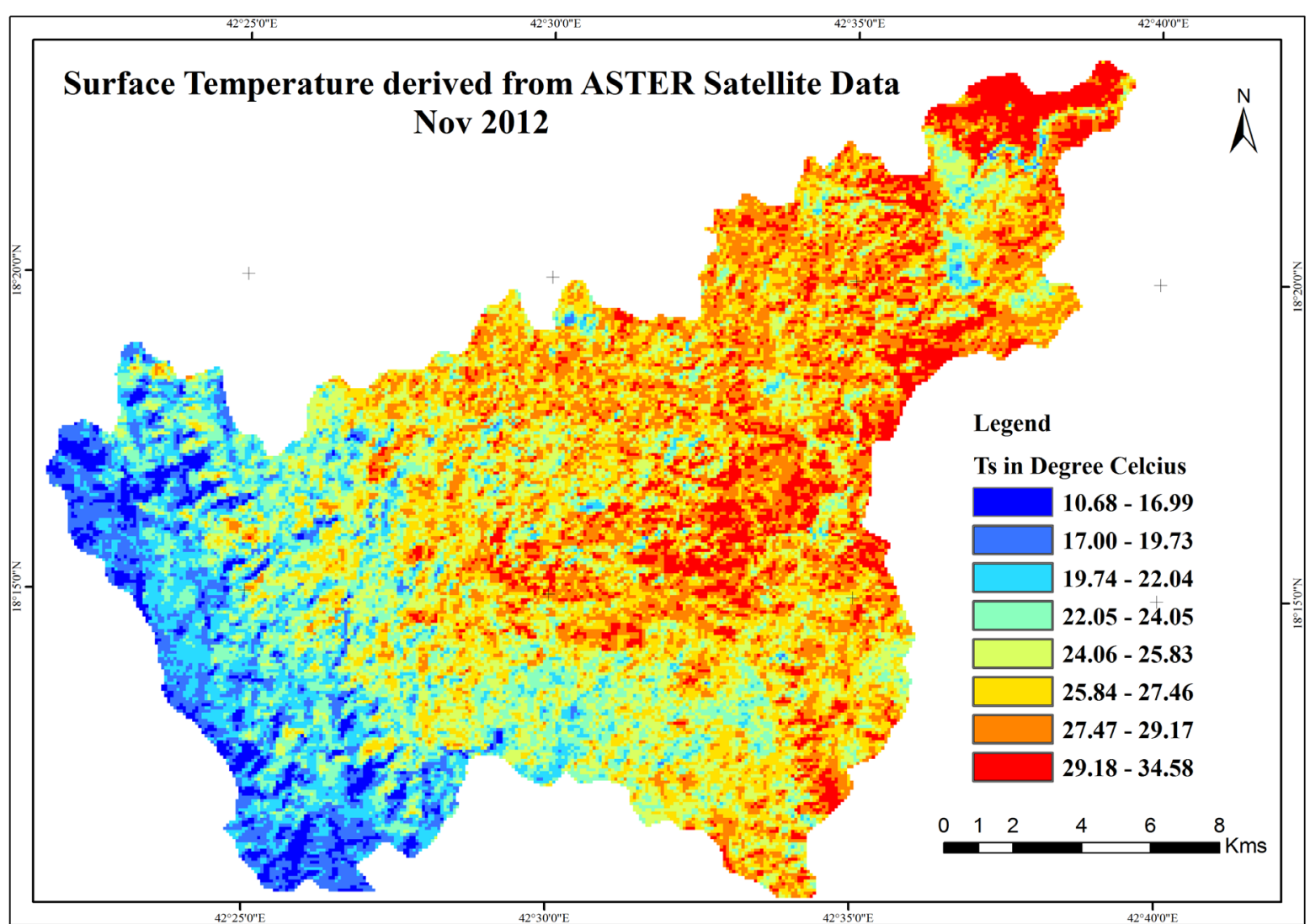

Figure 4. Spatial distribution of surface temperature of Abha using satellite dataset.

a mean value of $24.19^{\circ} \mathrm{C}$ and standard deviation of 3.63 (Table 3). It is observed that in the image, areas in the eastern and central eastern exhibit maximum Ts range that corresponds to the rock outcroplands and baresoil/ wastelands $\left(27^{\circ} \mathrm{C}\right.$ to $\left.34.58^{\circ} \mathrm{C}\right)$ and topographical at lower altitude. Areas in the west, south-west and north- west have lower Ts corresponding to dense and sparse vegetation and topographically high altitude. Water bodies exhibit minimum Ts.

Figure 5 and Table 3 show the estimated Ts values over different land use/land cover categories. Rock outcropland exhibits the highest Ts having mean Ts of $26.48^{\circ} \mathrm{C}$ with a standard deviation of 2.85 . Scrubs/bare soil values are also high having a mean value of $26.16^{\circ} \mathrm{C}$ with a standard deviation of 3.02 . These high temperatures vary associated with their thermal capacities and altitudinal effects. On the other hand water bodies show lower Ts having mean Ts of $18.07^{\circ} \mathrm{C}$ with a standard deviation of 2.89 . The variation in water depth (lake to wadies) is high at different locations caused high std. deviation. The impact of vegetation is clearly seen as low temperature values observed over dense vegetation, sparse vegetation, and agricultural cropland.

\subsection{Relationship between Surface Temperature with Elevation and NDVI}

Figure 6 shows the linear regression coefficient between Ts with elevation and NDVI with significance levels of 0.01. It is inferred that elevation and NDVI values tend to be negatively correlated with Ts. Coefficient of determination $\left(\mathrm{R}^{2}\right)$ for NDVI is 0.5154 and $\left(\mathrm{R}^{2}\right)$ for elevation is 0.6198 (Figure 7). It is observed that coefficient of determination $\left(\mathrm{R}^{2}\right)$ of Ts with elevation is better as compared with that for NDVI.

\subsection{Effects of Topographic Characteristics on the Spatial Distribution of Ts}

We examined the effects of topography on the spatial distribution of Ts. Jabal al Sooda is the highest point (2981 meters), situated in western part of the study area, whereas urban areas are located on the foot hills of Jabal al Sooda (Figure 8). The elevation varies from 1951 to 2991 meters from east to west. Spatial irregularities 
Mean Surface Temperature

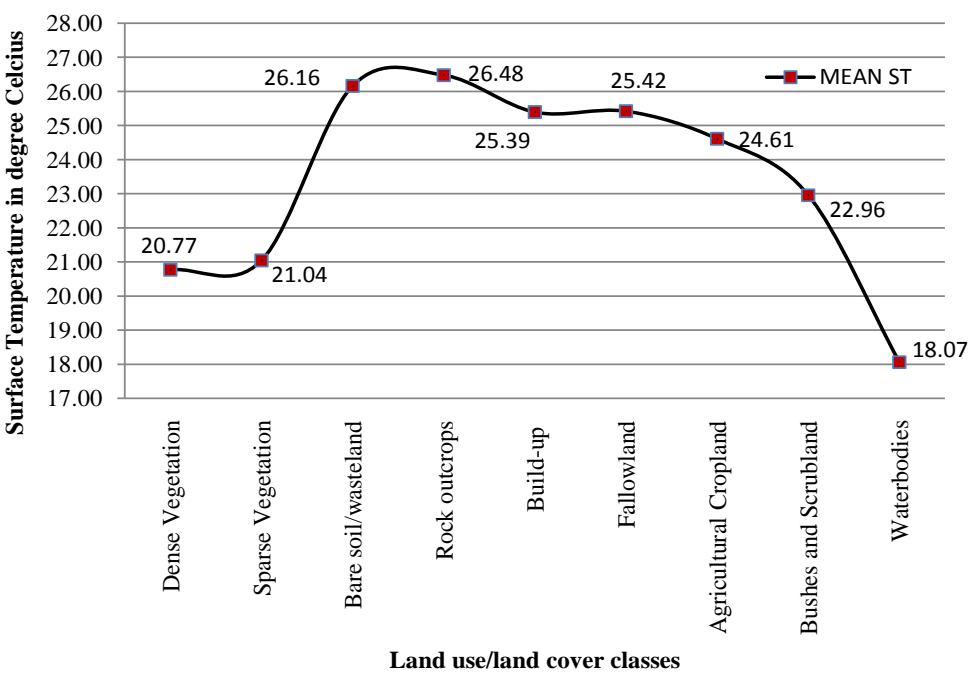

Figure 5. Relationship with mean surface temperature with land use/land cover.

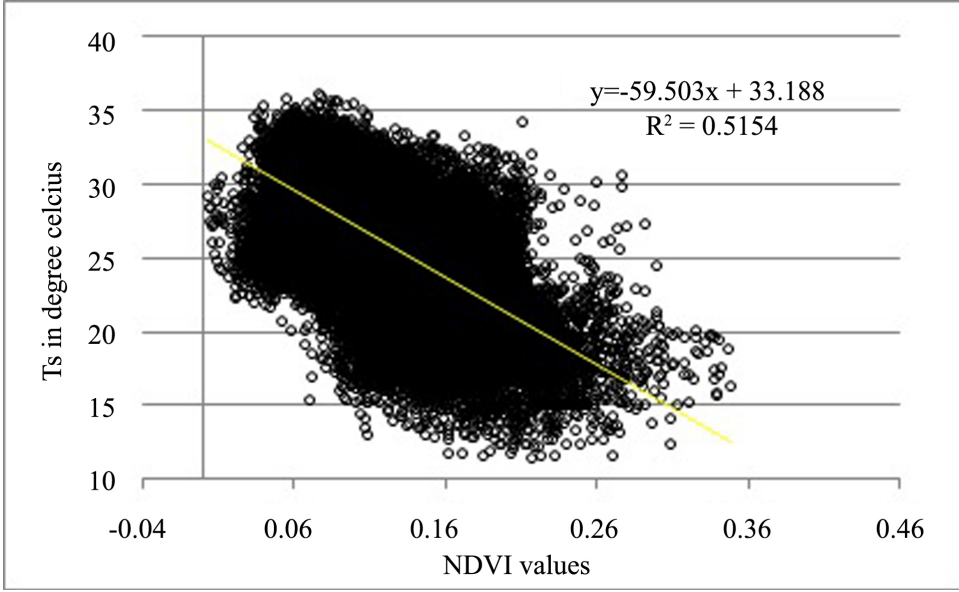

Figure 6. Linear correlationship between surface temperature with NDVI.

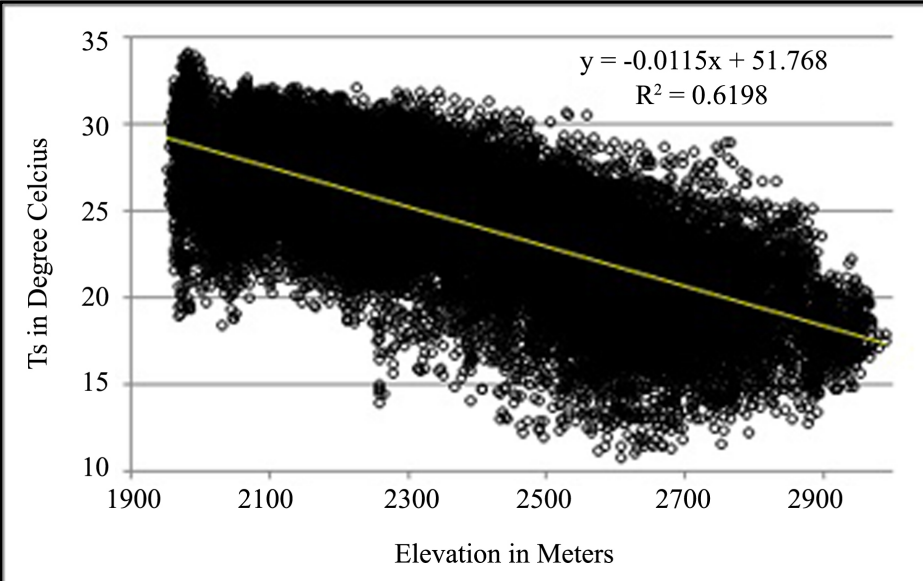

Figure 7. Linear correlationship between surafce temperture with elevation. 


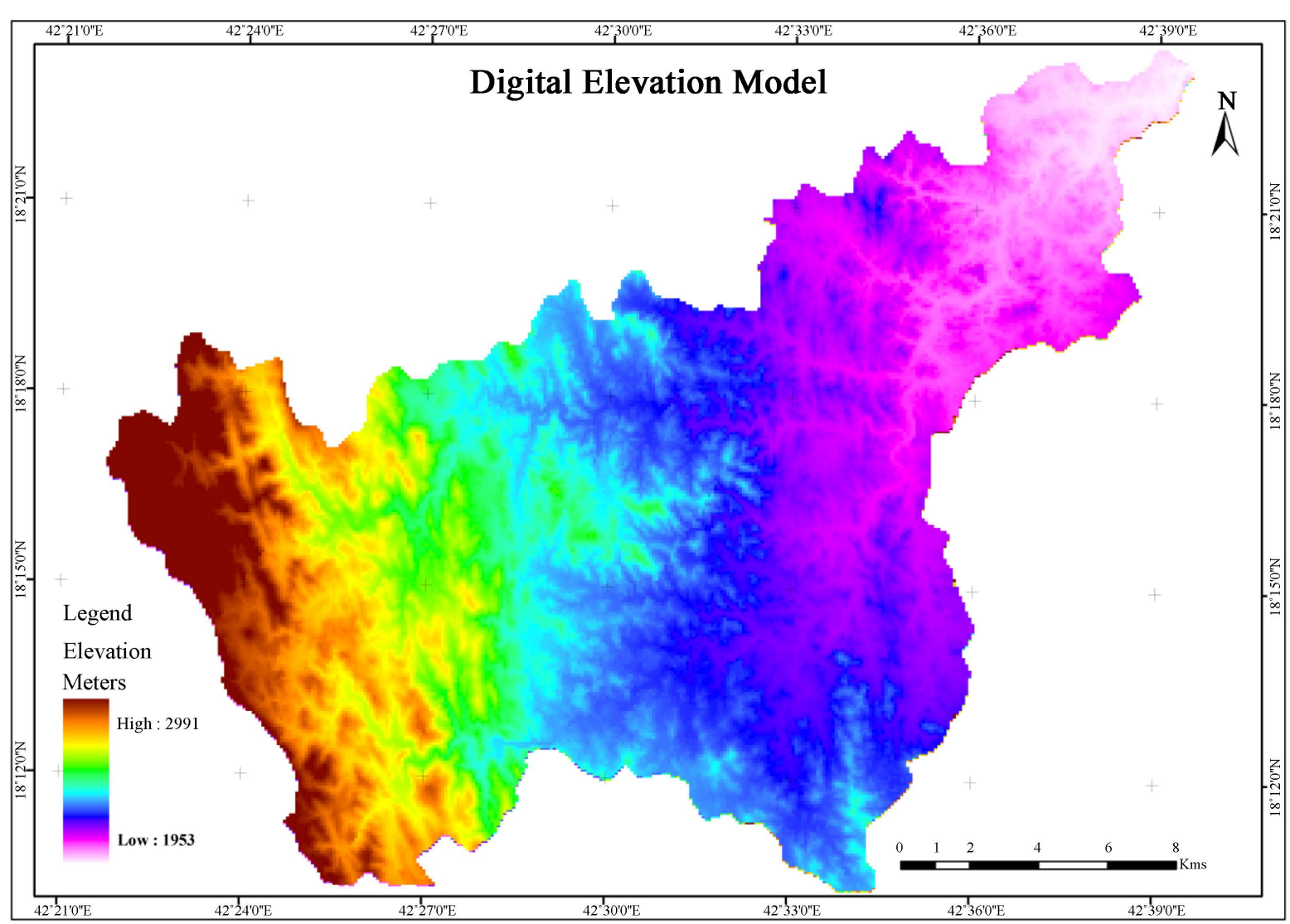

Figure 8. Spatial distribtiojn of digital elevation model of Abha.

Table 3. Statistics of Ts over different LULC with area.

\begin{tabular}{ccccccc}
\hline \multirow{2}{*}{ LULC Classes } & \multicolumn{5}{c}{ Overall Ts and Area } \\
\cline { 2 - 7 } & MIN ST ${ }^{\circ} \mathbf{C}$ & MAX ST $^{\circ} \mathbf{C}$ & MEAN ST ${ }^{\circ} \mathbf{C}$ & STD & Area in Km & Area in \% \\
\hline Built-Up & 12.22 & 33.82 & 25.39 & 2.79 & 34.79 & 9.40 \\
Water Bodies & 14.38 & 24.03 & 18.07 & 2.89 & 0.10 & 0.03 \\
Agricultural Cropland & 11.24 & 32.54 & 24.61 & 3.48 & 16.29 & 4.40 \\
Dense Vegetation & 11.04 & 30.16 & 20.77 & 3.30 & 2.14 & 0.58 \\
Sparse Vegetation & 10.68 & 32.90 & 21.04 & 3.59 & 39.63 & 10.71 \\
Fallow Land & 13.43 & 33.82 & 25.42 & 3.65 & 31.48 & 8.51 \\
Bushes/Scrubland & 11.46 & 32.87 & 22.96 & 3.52 & 40.54 & 10.96 \\
Bare Soil/Wasteland & 14.59 & 33.86 & 26.16 & 3.02 & 15.25 & 4.12 \\
Rock Outcroplands & 11.39 & 34.58 & 26.48 & 2.85 & 189.78 & 51.29 \\
Total & - & - & - & - & $\mathbf{3 7 0 . 0 0}$ & 100 \\
\hline
\end{tabular}

in the study area i.e. topography, land use, vegetation and wadies, were thought to affect the spatial distribution of Ts. Figure 9 shows the spatial relationship of Ts and elevation with their histograms. Their pattern reveals the effects of topography on Ts. Table shows the altitudinal effects of different LULC on their Ts. It indicates that at the elevation of 1950-2150 meters, Ts is high over built-up areas, with mean temperature of $25.23^{\circ} \mathrm{C}$ (Table 4 ). With increase in altitude, the mean Ts become low about $16.29^{\circ} \mathrm{C}$. These trends of Ts with altitude are also prevalent in all the LULC classes. The variations in hypsometry derivatives, has strong effect on Ts. 

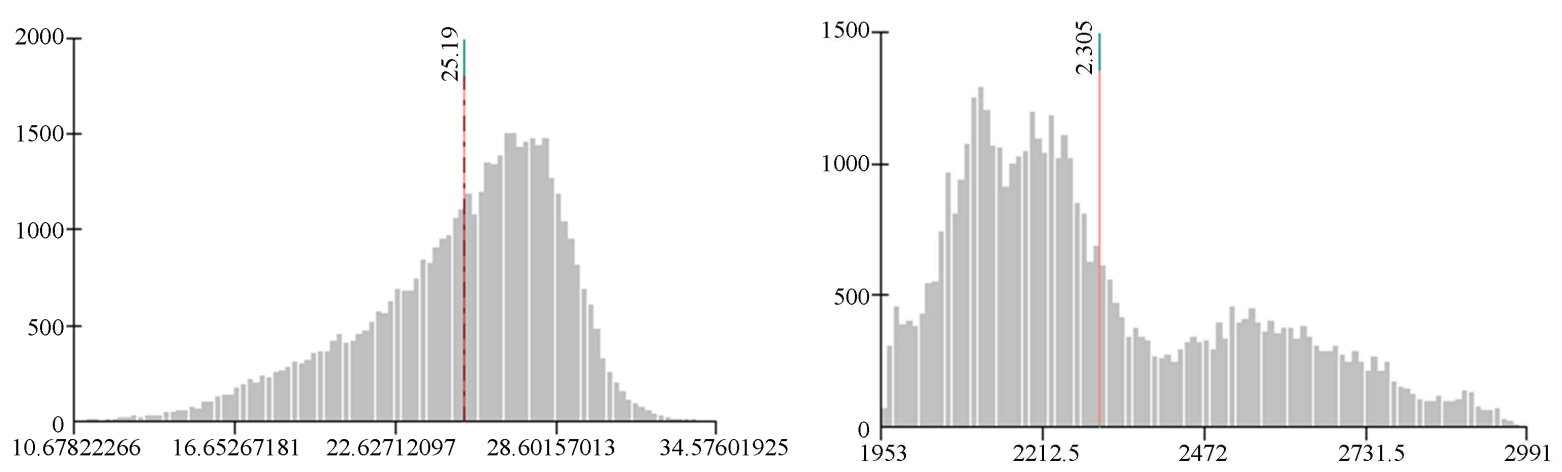

Figure 9. Relationship of Ts and elevation with their histograms.

Table 4. Statistics of LULC's Ts at different elevation.

\begin{tabular}{cccccc}
\hline LULC Classes & \multicolumn{2}{c}{ Ts $\left({ }^{\circ} \mathbf{C}\right.$ ) at Different Elevation Range (in meters) } \\
\hline & $\mathbf{1 9 5 0 - 2 1 5 0}$ & $\mathbf{2 1 5 1 - 2 3 5 0}$ & $\mathbf{2 3 5 1 - 2 5 5 0}$ & $\mathbf{2 5 5 1 - 2 7 5 0}$ & $\mathbf{2 7 5 1 - 2 9 9 1}$ \\
\hline Built-Up & 25.23 & 25.31 & 24.25 & 21.69 & 16.29 \\
Water Bodies & 18.07 & - & - & - & - \\
Agricultural Cropland & 26.98 & 25.80 & 23.41 & 20.64 & 18.93 \\
Dense Vegetation & 24.91 & 23.51 & 22.22 & 18.75 & 17.45 \\
Sparse Vegetation & 26.24 & 24.70 & 22.02 & 20.07 & 19.24 \\
Fallow Land & 27.72 & 26.78 & 24.70 & 22.93 & 20.72 \\
Bushes/Scrubland & 27.13 & 25.47 & 23.34 & 21.39 & 20.09 \\
Bare Soil/Wasteland & 27.01 & 26.63 & 24.22 & 20.89 & 18.89 \\
Rock Outcroplands & 27.80 & 26.70 & 24.42 & 21.34 & 19.58 \\
Total Area & $\mathbf{1 1 5 . 9 6}$ & $\mathbf{1 2 7 . 4 8}$ & $\mathbf{5 2 . 1 2}$ & $\mathbf{5 0 . 9 2}$ & $\mathbf{2 3 . 5 2}$ \\
\hline
\end{tabular}

\section{Conclusion}

Understanding the mechanism of the surface temperature's effect of land use is important for urban planning to enable greater control over thermal environments. In this study, land characterization analysis of surface temperature in the semi-arid mountainous city of Abha using remote sensing and GIS has been investigated. For this, Ts information is estimated from ASTER data to analyze the spatial distribution of the LULC effects on Ts. The spatial distribution of Ts was also affected by topography. Ts gradually decreased along the higher altitude land areas. That is, the cooling effect of the topography (hills) prolonged into the urban areas. The result showed that higher altitude regions effectively transfer the cool air to the surrounding low land use areas. Suitable mountainous land use utilization would help to expand the cooling effect. In the future, the results from this study could be used to help inform environmentally sustainable urban planning in semi-arid regions and to create processes that consider the characteristics of local weather environment in planning.

\section{Acknowledgements}

The author wishes to acknowledge the financial support by Deanship of Scientific Research, King Khalid University, KSA. NASA-USGS personnel at the land DAAC provided the latest ASTER-Terra satellite image was also greatly appreciated.

\section{References}

[1] Mallick, J., Kant, Y. and Bharath, B.D. (2008) Estimation of Land Surface Temperature over Delhi Using LANDSAT 
ETM+. Journal of Indian Geophysical Union, 12, 131-140.

[2] Quattrochi, D.A. and Luvall, J.C. (1999) Thermal Infrared Remote Sensing for Analysis of Landscape Ecological Processes: Methods and Applications. Landscape Ecology, 14, 577-598.

[3] Lillesand, T.M., Kiefer, R.W. and Chipman, J.W. (2004) Remote Sensing and Image Interpretation. 5th Edition, John Wiley \& Sons Inc., New York.

[4] Carlson, T.N., Dodd, J.K., Benjamin, S.G. and Cooper, J.N. (1981) Satellite Estimation of the Surface-Energy Balance, Moisture Availability and Thermal Inertia. Journal of Applied Meteorology, 20, 67-87. http://dx.doi.org/10.1175/1520-0450(1981)020<0067:SEOTSE>2.0.CO;2

[5] Balling, R.C. and Brazel, S.W. (1988) High-Resolution Surface Temperature Patterns in a Complex Urban Terrain. Photogrammetric Engineering and Remote Sensing, 54, 1289-1293.

[6] Dousset, B. (1989) AVHRR-Derived Cloudiness and Surface Temperature Patterns over the Los Angeles Area and Their Relationships to Land-Use. Proceedings of IGARSS-89, Vancouver, 13 July 1989, 2132-2137.

[7] Dousset, B. (1991) Surface Temperature Statistics over Los Angeles: The Influence of Land Use. Proceedings of IGARSS-91, Espoo, 3-6 June 1991, 367-371.

[8] Roth, M., Oke, T.R. and Emery, W.J. (1989) Satellite-Derived Urban Heat Islands from Three Coastal Cities and the Utilization of Such Data in Urban Climatology. International Journal of Remote Sensing, 10, 1699-1720. http://dx.doi.org/10.1080/01431168908904002

[9] Quattrochi, D.A. and Ridd, M.K. (1994) Measurement and Analysis of Thermal Energy Responses from Discrete Urban Surfaces Using Remote Sensing Data. International Journal of Remote Sensing, 15, 1991-2022. http://dx.doi.org/10.1080/01431169408954224

[10] Owen, T.W., Carlson, T.N. and Gillies, R.R. (1998) An Assessment of Satellite Remotely Sensed Land Cover Parameters in Quantitatively Describing the Climatic Effect of Urbanization. International Journal of Remote Sensing, 19, 1663-1681. http://dx.doi.org/10.1080/014311698215171

[11] Voogt, J.A. and Oke, T.R. (1998) Effects of Urban Surface Geometry on Remotely-Sensed Surface Temperature. International Journal of Remote Sensing, 19, 895-920. http://dx.doi.org/10.1080/014311698215784

[12] Weng, Q. and Quattrochi, D.A. (2006) Thermal Remote Sensing of Urban Areas: An Introduction to the Special Issue. Editorial, Remote Sensing and Environment, 104, 119-112.

[13] Mallick, J., Singh, C.K., Shashtri, S., Rahman, A. and Mukherjee, S. (2012) Land Surface Emissivity Retrieval Based on Moisture Index from LANDSAT TM Satellite Data over Heterogeneous Surfaces of Delhi City. International Journal of Applied Earth Observation and Geoinformation, 19, 348-358. http://dx.doi.org/10.1016/j.jag.2012.06.002

[14] Weng, Q.H., Lu, D.S. and Schubring, J. (2004) Estimation of Land Surface Temperature Vegetation Abundance Relationship for Urban Heat Island Studies. Remote Sensing of Environment, 89, 467-483. http://dx.doi.org/10.1016/j.rse.2003.11.005

[15] Geiger, R., Aron, R.H. and Todhunter, P. (2003) The Climate near the Ground. 6th Edition, Rowman and Littlefield Publishers, Lanham.

[16] Lookingbill, T.R. and Urban, D.L. (2003) Spatial Estimation of Air Temperature Differences for Landscape-Scale Studies in Montane Environments. Agricultural and Forest Meteorology, 114, 141-151.

[17] Kang, S., Lee, D. and Kimball, J.S. (2004) The Effects of Spatial Aggregation of Complex Topography on Hydroecological Process Simulations within a Rugged Forest Landscape: Development and Application of a Satellite-Based Topoclimatic Model. Canadian Journal of Forest Research, 34, 519-530.

[18] Hais, M. and Kucera, T. (2009) The Influence of Topography on the Forest Surface Temperature Retrieved from Landsat TM, ETM C and ASTER Thermal Channels. ISPRS Journal of Photogrammetry and Remote Sensing, 64, 585-591.

[19] Bailey, R.G. (1996) Ecosystem Geography. Springer, New York. http://dx.doi.org/10.1007/978-1-4612-2358-0

[20] McCune, B. (2007) Improved Estimates of Incident Radiation and Heat Load Using Non-Parametric Regression against Topographic Variables. Journal of Vegetation Science, 18, 751-754.

[21] Pierce, K.B., Lookingbill, T. and Urban, D. (2005) A Simple Method for Estimating Potential Relative Radiation (PRR) for Landscape-Scale Vegetation Analysis. Landscape Ecology, 20, 137-147.

[22] Mallick, J., Alashker, Y., Mohammad, S.A.D., Ahmed, M. and Hasan, M.A. (2013) Risk Assessment of Soil Erosion in Semi-Arid Mountainous Watershed in Saudi Arabia by RUSLE Model Coupled with Remote Sensing and GIS. Geocarto International, 29, 915-940. http://dx.doi.org/10.1080/10106049.2013.868044

[23] Mallick, J., Rahman, A. and Singh, C.K. (2013) Modeling Urban Heat Islands in Heterogeneous Land Surface and Its Correlation with Impervious Surface Area by Using Night-Time ASTER Satellite Data in Highly Urbanizing City, 
Delhi-India. Advances in Space Research, 52, 639-655.

[24] Short, N.M. (2010) The Remote Sensing Tutorial, Goddard Space Flight Center (GSCF), NASA. http://rst.gsfc.nasa.gov/Front/overview.html

[25] Mallick, J., Al-Wadi, H., Rahman, A. and Ahmed, M. (2014) Landscape Dynamic Characteristics Using Satellite Data for a Mountainous Watershed of Abha, Kingdom of Saudi Arabia. Environmental Earth Sciences, 72, 4973-4984. http://dx.doi.org/10.1007/s12665-014-3408-1

[26] Abulfatih, H.A. (1984) Wild Plants from Abha and the Surrounding Areas. Saudia Publishing and Distributing House, Jeddah, $125 \mathrm{p}$.

[27] Anderson, J.R., et al. (1976) A Land Use and Land Cover Classification System for Use with Remote Sensor Data. Geological Survey Professional Paper No. 964, U.S. Government Printing Office, Washington DC, 28.

[28] Hutchinson, M.F. and Dowling, T.I. (1991) A Continental Hydrological Assessment of a New Grid-Based Digital Elevation Model of Australia. Hydrological Processes, 5, 45-58. http://dx.doi.org/10.1002/hyp.3360050105

[29] Gillespie, A., Rokugawa, S., Matsunaga, T., Cothern, J.S., Hook, S. and Kahle, A.B. (1998) A Temperature and Emissivity Separation Algorithm for Advanced Space Borne Thermal Emission and Reflection Radiometer (ASTER) Images. IEEE Transactions on Geosciences and Remote Sensing, 36, 1113-1126. 
Scientific Research Publishing (SCIRP) is one of the largest Open Access journal publishers. It is currently publishing more than 200 open access, online, peer-reviewed journals covering a wide range of academic disciplines. SCIRP serves the worldwide academic communities and contributes to the progress and application of science with its publication.

Other selected journals from SCIRP are listed as below. Submit your manuscript to us via either submit@scirp.org or Online Submission Portal.
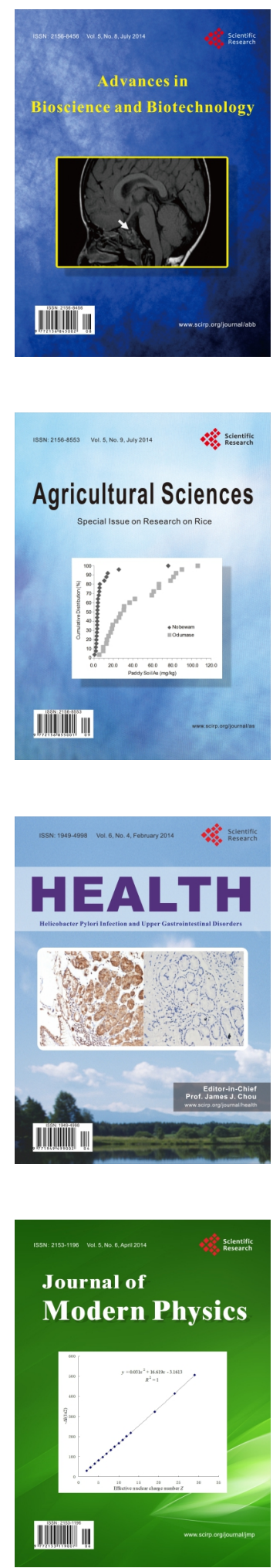
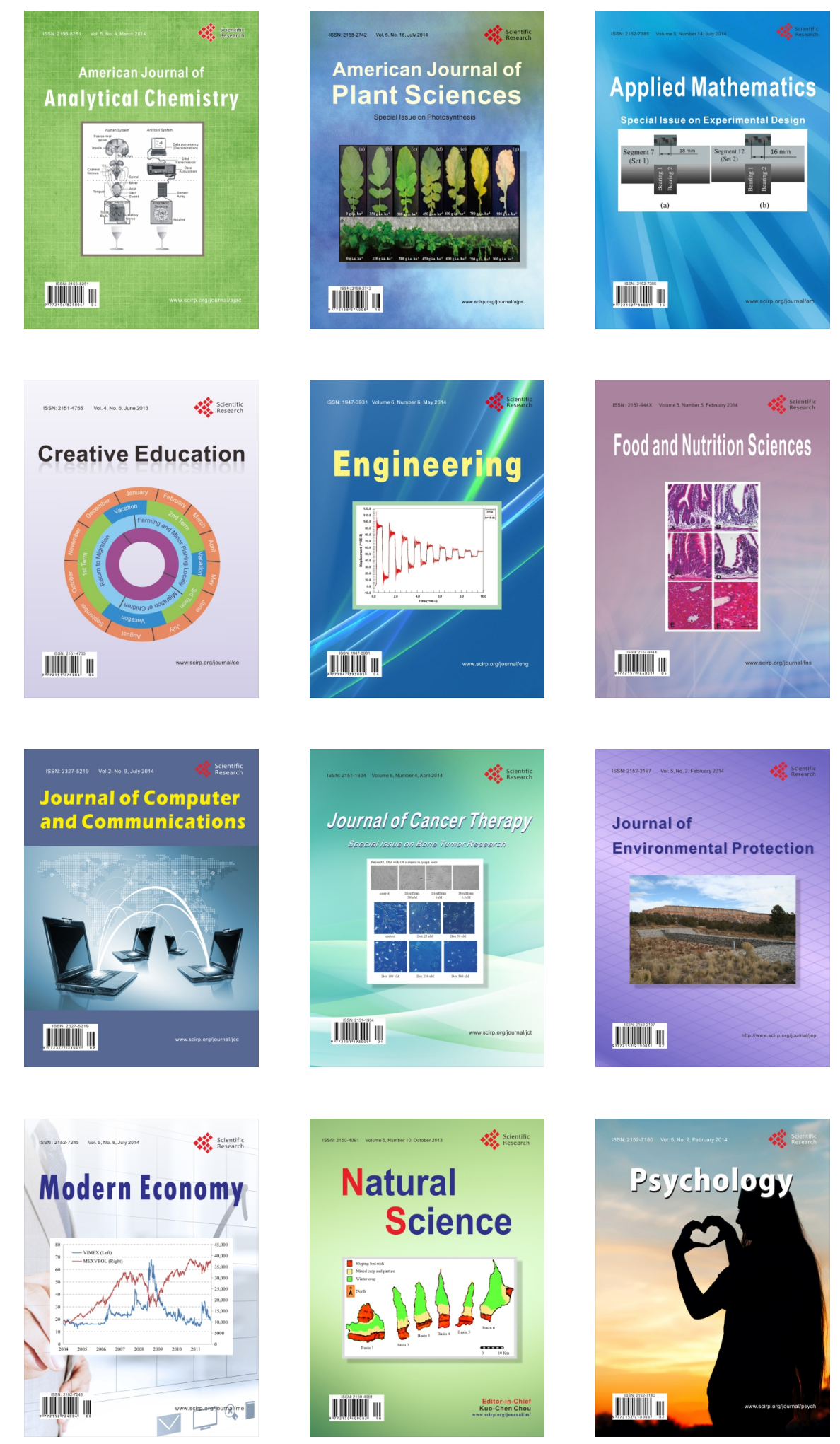